\title{
Analisis Rantai Nilai (Value Chain) Ikan Teri di Kabupaten Konawe Utara Value Chain Analysis of Anchovy Fish in North Konawe Regency
}

\author{
Oleh \\ Dian Wijayanto \\ Staf Pengajar Jurusan Perikanan FPIK Universitas Diponegoro \\ Kampus FPIK Undip, Jl. Prof. Soedarto SH, Tembalang, Semarang, 50275. \\ HP. +62815 954 2717, Email: dianwijayanto@yahoo.com
}

\begin{abstract}
Abstrak
Tujuan dari penelitian ini adalah untuk menganalisis value chain, marjin pemasaran, marjin keuntungan dan nilai tambah dari perikanan teri yang melibatkan nelayan, pengolah ikan teri kering, hingga pedagang ikan teri kering di Kabupaten Konawe Utara. Penelitian ini menggunakan data primer dan data sekunder. Data primer dikumpulkan melalui observasi lapangan dan wawancara mendalam (indepth interview) dengan para pemangku kepentingan. Data sekunder diperoleh dari publikasi dan dokumen terkait yang diterbitkan oleh instansi yang berwenang. Pengambilan sampel responden menggunakan metode purposive sampling. Metode analisis menggunakan analisis value chain, disertai perhitungan marjin pemasaran, marjin keuntungan dan nilai tambah. Hasil penelitian menunjukkan bahwa nelayan bagan perahu menikmati marjin pemasaran (15\%) dan marjin keuntungan (12\%) yang terbesar, selanjutnya diikuti oleh pengolah ikan teri dan pedagang ikan teri. Total nilai tambah perikanan teri di Kabupaten Konawe Utara adalah sebesar Rp. 6.325/kg teri kering.
\end{abstract}

Kata Kunci: Konawe Utara, marjin keuntungan, marjin pemasaran, nilai tambah, teri, value chain.

\section{Pendahuluan}

Kabupaten Konawe Utara merupakan salah satu kabupaten di Provinsi Sulawesi Tenggara yang telah menjadi salah satu sentra produksi ikan teri. Kabupaten Konawe Utara merupakan pemekaran dari Kabupaten Konawe, yaitu berdasarkan pada UU No 13 Tahun 2007 tentang Pembentukan Kabupaten Daerah Tingkat II di Provinsi Sulawesi Tenggara. Posisi Kabupaten Konawe Utara berada pada koordinat 02 $97^{\circ}-03^{\circ} 86^{\prime}$ Lintang Selatan dan $121^{\circ} 49^{\prime}-122^{\circ} 49$ Bujur Timur. Kabupaten Konawe Utara berbatasan dengan Kabupaten Morowali dan Kabupaten Konawe di sebelah utara, di sebelah timur berbatasan dengan Kabupaten Morowali dan Laut Banda, sebelah selatan berbatasan dengan Kabupaten Konawe dan sebelah barat berbatasan dengan Kabupaten Konawe. Luas wilayah Kabupaten Konawe Utara adalah 500.339 ha serta memiliki perairan seluas $11.960 \mathrm{Km}^{2}$. Kabupaten Konawe Utara terdiri dari 10 kecamatan, yaitu: Sawa, Motui, Lembo, Lasolo, Molawe, Asera, Andowia, Oheo, Langgikima dan Wiwirano. Pada tahun 2014, jumlah penduduk Kabupaten Konawe Utara adalah 57.077 jiwa. Pada tahun 2014, sekitar 59,81\% dari angkatan kerja penduduk Kabupaten Konawe utara bekerja pada kelompok sektor Pertanian, Perkebunan, Kehutanan, Perburuan dan Perikanan (BPS Kabupaten Konawe Utara, 2015) ${ }^{1}$. 
Tabel 1. Jumlah Kapal Perikanan dan Alat Penangkap Ikan Tahun 2014

\begin{tabular}{|l|r|}
\hline Jenis Armada Penangkap Ikan & \multicolumn{1}{|c|}{ Jumlah } \\
\hline Kapal Perikanan & 1.018 unit \\
\hline Perahu Tanpa Motor & 632 unit \\
\hline Perahu Motor Tempel & 189 unit \\
\hline Kapal Motor & 876 unit \\
\hline Alat Penangkap Ikan & 50 unit \\
\hline Pukat & 301 unit \\
\hline Payang & 1.194 unit \\
\hline Jaring & 5.818 unit \\
\hline Pancing &
\end{tabular}

Sumber: BPS Kabupaten Konawe Utara (2015) ${ }^{1}$

Tabel 2. Produksi Perikanan Tahun 2014

\begin{tabular}{|l|r|}
\hline \multicolumn{1}{|c|}{ Jenis } & \multicolumn{1}{|c|}{ Jumlah } \\
\hline Produksi Tangkap dan Budidaya & $2.243,70$ ton \\
\hline Produksi Budidaya Tambak & 48,22 ton \\
\hline Produksi Budidaya Kolam & $11.766,87$ ton \\
\hline Produksi Perikanan Tangkap & $4.485,0$ ton \\
\hline Produksi Perikanan Laut & $6.942,0$ ton \\
\hline Produksi Ikan & $97,5 \mathrm{Kg}$ \\
\hline Produksi Kepiting & 117,9 ton \\
\hline Produksi Udang & 16,2 ton \\
\hline Produksi Kerang & 108,30 ton \\
\hline Produksi Ikan Lainnya & Rp. 2.695 Juta \\
\hline Produksi dan Nilai Produksi Perairan Umum & $11.658,57$ ton \\
\hline Produksi Perairan Umum & Rp. 314.781 Juta \\
\hline Nilai Produksi Perairan Umum & \\
\hline Produksi dan Nilai Produksi Perikanan laut & \\
\hline Produksi Perikanan Laut & \\
\hline Nilai Produksi Perairan Umum & \\
\hline
\end{tabular}

Sumber: BPS Kabupaten Konawe Utara (2015) ${ }^{1}$

Ikan teri (Stolephorus sp.) termasuk ikan pelagis kecil yang memiliki nilai jual tinggi. Harga ikan teri relatif beragam, tergantung jenis produk, daerah, kualitas produk dan musim ikan teri. Harga ikan teri secara harian mengalami fluktuasi. Harga ikan teri termasuk mahal, dimana ikan teri kering harganya dapat mencapai Rp. 80.000/kg. Terdapat beberapa jenis ikan ancovies di dunia, yaitu 145 spesies dalam 17 genera yang tersebar di Samudera Hindia, Samudera Atlantik, Samudera Pasifik dan Laut Mediterania. Ikan anchovies termasuk komoditas perdagangan perikanan yang utama di dunia. Produksi anchovies di dunia di dunia mendekati 10,5 juta ton pada tahun 2009, dimana produksi terbesar berasal dari jenis anchoveta (peruvian anchovy), yaitu mencapai 65\%. Sedangkan jenis Stolephorus sp yang banyak teradapat di perairan Indonesia, produksinya sekitar 3\% dari produksi anchovies di dunia. Pada tahun 2009, Indonesia sebagai produsen ikan teri berada pada peringkat 8 dunia, dengan jumlah produksinya sebesar 203,7 ribu ton. Lima besar produsen anchovies terbesar di dunia adalah Peru, Chilie, China, Turki dan Jepang. Perdagangan anchovies di dunia yang paling besar dalam bentuk beku (frozen). Jepang merupakan produsen utama ikan teri beku di dunia. Korea Selatan merupakan produsen ikan teri asin terbesar di dunia. Peru merupakan 
produsen ikan teri "preserved dan prepared" (termasuk dalam bentuk kaleng, dan diproses dengan minyak olive) terbesar di dunia. Negara pengimpor ikan teri segar dan beku antara lain Spanyol, Turki dan Italia. Sedangkan negara pengimpor ikan teri asin yang utama di dunia antara lain Spanyol, Italia, Maroko dan Albania. Negara pengekspor ikan teri segar dan beku antara lain Italia, Kroasia, Perancis, dan Yunani. Negara pengekspor ikan teri "preserved and prepared" antara lain Maroko, Peru, Italia dan Spanyol. Negara pengekspor ikan teri asin antara lain Argentina, Kroasia, Spanyol dan Italia (Eurofish International Organisation, 2012). Oleh karena itu, ikan teri dapat dikategorikan produk bernilai jual tinggi dan prospektif dipasarkan, baik di dalam negeri maupun perdagangan internasional.

Keberadaan ikan teri di perairan Kabupaten Konawe Utara relatif ada sepanjang tahun, atau tidak mengenal musim. Oleh karena itu, Kabupaten Konawe Utara berpotensi untuk dikembangkan sebagai sentra industri berbahan baku ikan teri. Terkait dengan pengembangan industri perikanan teri di Kabupaten Konawe Utara, maka diperlukan kajian komprehensif, termasuk kajian valau chain (rantai nilai) ikan teri, mulai dari produsen (nelayan), hingga konsumen. Tujuan dari penelitian ini adalah untuk menganalisis value chain, marjin pemasaran dan marjin keuntungan dari para pelaku usaha produksi ikan teri, mulai dari nelayan, pengolah ikan teri, hingga pedagang ikan teri. Selain itu juga dihitung nilai tambah dari perikanan teri di Kabupaten Konawe Utara.

\section{Metode Penelitian}

Penelitian yang dilakukan termasuk jenis penelitian terapan, yaitu untuk menghasilkan temuan yang diperlukan dalam penyelesaian masalah, khususnya permasalahan value chain ikan teri di Kabupaten Konawe Utara.

\section{Pengumpulan Data}

Penelitian ini menggunakan data primer dan data sekunder. Data primer dikumpulkan melalui observasi lapangan dan wawancara mendalam (indepth interview) dengan para pemangku kepentingan, antara lain nelayan bagan perahu dengan fish target-nya adalah ikan teri, pengolah ikan teri kering, pedagang ikan teri olahan, penyuluh perikanan dan pegawai Dinas Kelautan dan Perikanan. Sedangkan data sekunder diperoleh dari publikasi dan dokumen terkait yang diterbitkan oleh instansi yang berwenang, yaitu Badan Pusat Statistik (BPS) Kabupaten Konawe Utara, Dinas Kelautan dan Perikanan (DKP) Kabupaten Konawe Utara dan DKP Provinsi Sulawesi Tenggara. Pengambilan sampel responden menggunakan metode purposive sampling.

\section{Analisis Value Chain}

Value chain merupakan seluruh proses yang diperlukan untuk menyediakan barang atau jasa melalui beberapa fase produksi, mendistribusikan ke konsumen akhir dan termasuk layanan purna jual. Terdapat perbedaan antara value chain dan supply chain, dimana supply chain lebih fokus pada efisiensi biaya untuk mengoptimalkan keuntungan, sedangkan value chain menekankan pada penciptaan nilai tambah dalam mengoptimalkan keuntungan.

Analisis value chain dilakukan dengan mengidentifikasi pelaku value chain, marjin keuntungan masing-masing pelaku, serta permasalahan yang dihadapi beserta dengan penyebab dan alternatif solusinya. Menurut Gudmundsson (2006), secara umum analisis value chain untuk produk seafood meliputi: harvesting, primary processing, secondary processing, wholesale, retail dan consumer. Untuk usaha penangkapan ikan, diantaranya diperhitungkan bagi hasil anak buah kapal (ABK), biaya bahan bakar, biaya pemeliharaan 
alat tangkap, biaya tetap, biaya lain-lain dan marjin. Sedangkan pada secondary processing diperhitungkan biaya tenaga kerja, biaya bahan baku, biaya energi, biaya pengemasan, biaya transportasi, biaya pemeliharaan, biaya overhead, biaya lain-lain dan marjin. Penelitian analisis value chain telah dilakukan para peneliti, diantaranya Achchuthan and Kajananthan (2012), Odebiyi, et al. (2013), Dzanja, et al. (2013), Jung (2014), Phiri, et al. (2013), Kabu and Tira (2015), Acharyu, et al. (2015), O'Neill (2013), serta Mwirigi and Theuri (2012).

Gambar 1. Pelaku Value Chain Ikan Teri

\begin{tabular}{|c|c|c|c|c|}
\hline $\begin{array}{c}\text { Pensuplai Faktor } \\
\text { Produksi }\end{array}$ & $\begin{array}{c}\text { Nelayan } \\
\text { Bagan Perahu }\end{array}$ & $\begin{array}{c}\text { Pengolah Ikan } \\
\text { Teri Kering }\end{array}$ & $\begin{array}{c}\text { Pedagang } \\
\text { Ikan }\end{array}$ & $\begin{array}{l}\text { Konsumen } \\
\text { Lokal dan } \\
\text { Luar Daerah }\end{array}$ \\
\hline
\end{tabular}

\section{Analisis Marjin Keuntungan dan Marjin Keuntungan}

Untuk menganalisis marjin keuntungan dan marjin pemasaran, dipergunakan beberapa rumus sebagai berikut (Phiri, et al., 2013):

$\begin{array}{ll}\mathrm{MM} & =\mathrm{SP}-\mathrm{PP} \\ \mathrm{MP} & =\mathrm{SP}-(\mathrm{PP}+\mathrm{MC}) \\ \mathrm{ME} & =\mathrm{FP} /\left(\mathrm{MC}_{\mathrm{T}}+\mathrm{MM}_{\mathrm{T}}\right) \\ \mathrm{FP} & =\mathrm{SP}-\mathrm{MC}\end{array}$

Dimana MM adalah marketing margin, MP adalah marketing profit, SP adalah sale price, $\mathrm{PP}$ adalah purchase price, serta MC adalah marketing cost. Sedangkan ME adalah marketing efficiency index, $\mathrm{FP}$ adalah net price, $\mathrm{MC}_{\mathrm{T}}$ adalah total marketing cost, $\mathrm{MM}_{\mathrm{T}}$ adalah total marketing margin. Jika $\mathrm{ME} \geq 1$, maka saluran distribusi dapat dikatakan efisien dan jika $\mathrm{ME}<1$, maka saluran distribusi dapat dikatakan tidak efisien.

\section{Hasil dan Pembahasan}

Produksi teri Indonesia memiliki tren naik. Pada tahun 2005, Indonesia memproduksi ikan teri sebesar 151.926 ton dan meningkat menjadi 191.094 ton pada tahun 2013, dimana terjadi pertumbuhan rata-rata sebesar 3,28\% per tahun. Kabupaten Konawe Utara termasuk dalam WPP 713, yang meliputi Selat Makassar, Teluk Bone, Laut Flores dan Laut Bali. Produksi ikan teri di WPP 713 mengalami juga fluktuasi dengan kecenderungan mengalami peningkatan. Pada tahun 2005, produksi teri di WPP 713 mencapai 21.819 ton (14,4\% dari produksi nasional) dan naik menjadi 26.489 ton (13,9\% dari produksi nasional) pada tahun 2013 (KKP, 2104).

Menurut BPS Prov. Sulawesi Tenggara (2013), produksi ikan teri kering Provinsi Sulawesi Tenggara sebesar 15.335 ton dengan nilai sebesar Rp. 690 miliyar pada tahun 2012. Produksi perikanan laut Kabupaten Konawe Utara mencapai 19.679 ton dengan nilai produksi sebesar Rp. 82 miliyar.

Kabupaten Konawe Utara mengandalkan sub sektor perikanan sebagai salah satu sumber pertumbuhan ekonomi utama. Sektor pertanian (termasuk perikanan) menyumbang PDRB sebesar 42,82\% pada tahun 2014, dengan laju pertumbuhan riil PDRB sebesar $8 \%$. Sedangkan sumbangsih sub sektor perikanan merupakan yang terbesar dalam sektor pertanian, yaitu mencapai 39,62\%. PDRB perikanan atas dasar harga berlaku Kabupaten Konawe Utara mencapai Rp. 413.083,97 juta pada tahun 2014 atau sekitar 16,96\% dari total PDRB, dengan laju pertumbuhan PDRB atas dasar harga berlaku sebesar 10,01\% (BPS Kabupaten Konawe Utara, 2015) ${ }^{2}$. 
Kecamatan Lasolo merupakan salah satu fishing base utama perikanan teri di Kabupaten Konawe Utara. Pada tahun 2014, penduduk Kecamatan Lasolo yang bekerja di sub sektor perikanan adalah 1.783 orang atau $24,52 \%$ dan jumlah rumah tangga perikanan laut (penangkapan) sebanyak 546 RTP (74\%), sedangkan rumah tangga perikanan budidaya sebesar 189 RTP (26\%) (BPS Kabupaten Konawe Utara, 2015) ${ }^{3}$. Uraian di atas menunjukkan bahwa potensi produksi ikan teri di Kabupaten Konawe Utara dapat diandalkan bagi pertumbuhan ekonomi sub sektor perikanan di Kabupaten Konawe Utara.

\section{Usaha Bagan Perahu}

Keberadaan bagan perahu di Kabupaten Konawe Utara telah menggeser keberadaan bagan tancap. Hasil tangkapan bagan perahu yang lebih besar menyebabkan nelayan bagan tancap beralih menggunakan bagan perahu. Nelayan yang memulai usaha di Kabupaten Konawe Utara merupakan pendatang (yaitu dari Suku Bugis) dan pernah terjadi konflik dengan nelayan setempat. Namun, konflik tersebut telah terselesaikan, dan nelayan setempat justru mengadopsi teknologi bagan perahu yang dibawa nelayan pendatang.

Bagan perahu termasuk dalam klasifikasi lift nets, dimana bagan perahu di Kabupaten Konawe Utara berbahan baku utama dari kayu dan bambu. Bentuk jaring persegi empat yang diikatkan pada bingkai yang terbuat dari kayu dan bambu. Jenis jaring yang di gunakan adalah jaring waring. Bagian tengahnya terdapat bangunan rumah (berukuran 4 meter x 9 meter) yang berfungsi sebagai tempat istirahat, tempat penyimpanan mesin. Bagan perahu dilengkapi roller sebagai alat bantu untuk menarik jaring. Panjang perahu adalah 26 meter, lebar 2 meter dan tinggi 3 meter. Sedangkan lebar sayap bagan adalah 24 meter. Katir atau sayap bagan berada di samping kanan dan kiri, dimana katir terbuat dari bambu dan terpasang secara vertikal dan horisotal, dengan panjang katir 26 meter. Jaring yang digunakan berukuran $0,5 \mathrm{~cm}$, luas waring $5.000 \mathrm{~m}^{2}$ dengan bahan waring menggunakan polyphropylen. Untuk menopang tiang utama, digunakan kawat baja berjumlah 400 biji berdiameter $8 \mathrm{~mm}$. Kawat ini di pasang di tiang utama dan dipancangkan di kerangka bagan. Tiang utama terbuat dari kayu ulin dengan lebar $25 \mathrm{~cm}$, tinggi 11 meter dan tiang utama berjumlah.

Lampu yang digunakan sebanyak 60 buah lampu, terdiri dari 2 buah lampu merkuri dengan tenaga 200 watt, dan 58 buah lampu TL dengan tenaga 25 watt. Roller terdiri dari 4 buah ( 2 buah roller utama dan 2 buah roller). Serok digunakan sebagai alat bantu penangkapan ikan. Basket digunakan sebagai wadah hasil tangkapan setelah disortir, berbahan sterofoam dan jumlahnya adalah 30 buah. Mesin bantu menggunakan mesin diesel berdaya maksimum 2.200 watt dan berbahan solar. Cara pengoperasian alat antara lain: setting sekitar 15 menit, immersing selama 3-4 jam dan hauling. Sebelum dilakukan pengangkatan jaring, maka dilakukan pemadaman lampu secara bertahap, mulai dari bagian sayap bagan, dan terakhir lampu bagian tengah. Setelah dinding jaring mulai terlihat, lampu bagian tengah di padamkan sehingga ikan tertangkap oleh jaring. Setelah bingkai jaring naik ke atas permukaan air, maka tali penggantung pada ujung dilepas dan jaring dibawa mendekati dek kapal melewati kerangka bagan. Jaring kemudian ditarik menuju dek. Hasil tangkapan yang telah terkumpul diangkat ke dek kapal dengan menggunakan serok, dan selanjutnya dilakukan penyortiran ikan. 
Tabel 3. Marjin Keuntungan dan Marjin Pemasaran Nelayan Bagan Perahu

\begin{tabular}{|c|c|c|}
\hline Jenis Biaya dan Harga Jual & Rp/Trip & $\mathrm{Rp} / \mathrm{Kg}$ Basah \\
\hline Penyusutan Aset Kapal dan Mesin & 109.890 & 246 \\
\hline Bahan Bakar Minyak & 560.000 & 1.254 \\
\hline Es Batu & 60.000 & 134 \\
\hline Perbekalan & 500.000 & 1.120 \\
\hline Perijinan (SIUP dan SIPI) & 4.762 & 11 \\
\hline Oli & 48.352 & 108 \\
\hline Gaji ABK & 1.043 .478 & 2.337 \\
\hline Perawatan Aset & 146.520 & 328 \\
\hline Jumlah Biaya Produksi, 273 trip/thn (a) & 2.473 .002 & 5.538 \\
\hline Retribusi Sandar Kapal & 5.000 & 11 \\
\hline Retribusi Penjualan Ikan & 57.933 & 130 \\
\hline Komunikasi & 4.348 & 10 \\
\hline Jumlah Biaya Penjualan (b) & & 151 \\
\hline Harga Jual (c) & & 6.487 \\
\hline Marjin Pemasaran $(\mathrm{d}=\mathrm{c}-\mathrm{a})$ & & 949 \\
\hline Marjin Keuntungan $(e=c-a-b)$ & & 798 \\
\hline Asumsi Produksi dan Harga & \multicolumn{2}{|c|}{ Nilai } \\
\hline Asumsi Rata-Rata Produksi (Kg/Trip) & & 447 \\
\hline Asumsi Harga Rata-Rata (Rp/Kg) & & 6.487 \\
\hline
\end{tabular}

Hasil penelitian membuktikan bahwa marjin pemasaran usaha bagan perahu adalah sebesar 15\%, sedangkan marjin keuntungan sebesar 12\%. Marjin tersebut bersifat moderat. Terbukti bahwa usaha perikanan tangkap dengan alat tangkap bagan perahu di Kabupaten Konawe Utara relatif menguntungkan. Sedangkan proporsi biaya terbesar adalah gaji anak buah kapal, pengadaan bahan bakar dan perbekalan. Oleh karena itu, pengaturan kerja 8 ABK perlu diatur agar efisien dan efektif sehingga menghasilkan tangkapan yang optimal. Demikian pula dengan pengadaan bahan bakar, perbaikan teknologi yang lebih hemat bahan bakar perlu dipertimbangkan oleh setiap pelaku usaha bagan perahu di Kabupaten Konawe Utara.

\section{Usaha Pengolahan Ikan Teri}

Ikan teri yang ditangkap oleh nelayan dibawa di fishing base, dimana pangkalan pendaratan ikan di Desa Tinobu sebagai pusat kegiatan perikanan teri masih bersifat alamiah, tanpa didukung oleh dermaga, dan jetty. Hasil tangkapan nelayan selanjutnya dibeli oleh masyarakat pesisir yang berprofesi sebagai pengolah ikan. Ikan teri segar tersebut dicuci dengan air laut dan dikeringkan dengan mengandalkan panas matahari. Kalau cuaca sedang panas, maka proses penjemuran dapat berlangsung dalam 2 hari. Setelah ikan teri sudah kering, maka ikan teri tersebut dibeli oleh para pedagang yang datang ke lokasi. 
Tabel 4. Marjin Keuntungan dan Marjin Pemasaran Pengolah Teri Kering

\begin{tabular}{|c|c|c|}
\hline Jenis Biaya dan Harga Jual & Rp/Hari & $\mathrm{Rp} / \mathrm{Kg}$ Kering \\
\hline Penyusutan Aset & 7.308 & 116 \\
\hline Peralatan Pendukung & 366 & 6 \\
\hline Konsumsi Harian & 50.000 & 794 \\
\hline Bahan Baku & 2.043 .462 & 32.436 \\
\hline Perawatan Aset & 8.791 & 140 \\
\hline Jumlah Biaya Produksi, 273 hari/thn (a) & & 33.491 \\
\hline Bahan Kemas & 63.000 & 1.000 \\
\hline Komunikasi & 1.587 & 69 \\
\hline Biaya Penjualan (b) & & 1.069 \\
\hline Harga Jual (c) & & 36.000 \\
\hline Marjin Pemasaran $(d=c-a)$ & & 2.509 \\
\hline Marjin Keuntungan $(e=c-a-b)$ & & 1.440 \\
\hline Asumsi & \multicolumn{2}{|c|}{ Nilai } \\
\hline Bahan Baku Basah (Kg/Hari) & & 315 \\
\hline Rendemen $(\%)$ & & $20 \%$ \\
\hline Bahan Jadi (Kg/Hari) & & 63 \\
\hline
\end{tabular}

Hasil penelitian membuktikan bahwa marjin pemasaran usaha pengolahan teri kering adalah sebesar 7\%, sedangkan marjin keuntungan sebesar 4\%. Marjin tersebut lebih kecil dari usaha bagan perahu, namun resiko gagal bisnis dari bagan perahu relatif lebih besar dibandingkan pengolahan ikan teri kering. Ikan teri kering memiliki daya tahan/awet relatif lama, bahkan dapat mencapai 6 bulan hingga 1 tahun. Sedangka usaha bagan perahu, memiliki resiko gagal menangkap ikan dalam jumlah yang menguntungkan, tergantung kondisi perairan dan keahlian nelayan dalam menangkap ikan. Proporsi biaya terbesar adalah pengadaan bahan baku, oleh karena itu penanganan bahan baku (ikan teri segar) menjadi faktor yang sangat menentukan keberhasilan usaha pengolahan ikan teri kering.

\section{Usaha Pedagang Ikan Teri}

Pedagang ikan teri kering berasal dari Kabupaten Konawe Utara, maupun dari Kota Kendari. Penjualan ikan teri kering mencakup pemasaran lokal (Kabupaten Konawe Utara) dan lintas daerah (Provinsi Sulawesi Tenggara, terutama Kota Kendari). 
Tabel 5. Marjin Keuntungan dan Marjin Pemasaran Pedagang Teri Kering

\begin{tabular}{|l|r|r|}
\hline \multicolumn{1}{|c|}{ Jenis Biaya dan Harga Jual } & \multicolumn{1}{c|}{ Rp/Hari } & Rp/Kg Kering \\
\hline Pembelian Ikan Kering, 15 hari per bulan (a) & 14.400 .000 & 36.000 \\
\hline Penyusutan Aset & 37.850 & 158 \\
\hline BBM & 127.500 & 531 \\
\hline Bahan Kemas & 240.000 & 1.000 \\
\hline Perawatan Aset & 40.000 & 167 \\
\hline Perbekalan dan Akomodasi & 300.000 & 1.250 \\
\hline Biaya Penjualan, 300 Hari per Tahun (b) & & 3.106 \\
\hline Harga Jual (c) & & 40.000 \\
\hline Marjin Pemasaran (d = c - a) & & 4.000 \\
\hline Marjin Keuntungan (e = c - a - b) & & 894 \\
\hline \multicolumn{2}{|c|}{ Asumsi } & \\
\hline Pembelian Ikan Teri Kering (Kg/Hari), 15 Hari/Bulan & & 400 \\
\hline Penjualan Ikan Teri Kering (Kg/Thn) & & 72.000 \\
\hline Penjualan Ikan Teri Kering (Kg/Hari), 300 Hari/Tahun & & 240 \\
\hline
\end{tabular}

Hasil penelitian membuktikan bahwa marjin pemasaran usaha bagan perahu adalah sebesar $10 \%$, sedangkan marjin keuntungan sebesar $2 \%$. Marjin keuntungan usaha penjualan ikan teri memang lebih kecil dibandingkan dengan usaha bagan perahu dan pengolahan ikan teri kering, namun omsetnya adalah yang paling besar per pelaku. Resiko gagal usaha dari penjualan ikan teri kering juga relatif kecil dibandingkan usaha bagan perahu, mengingat daya tahan teri kering yang relatif lama. Proporsi biaya terbesar adalah biaya pembelian barang dagangan (ikan teri kering). Oleh karena itu, penanganan barang dagangan harus mendapatkan prioritas perhatian, agar tidak mengalami kerusakan dan dapat terjual dengan optimal.

\section{Analisis Nilai Tambah}

Berdasarkan hasil analisis marjin keuntungan dari pelaku usaha bagan perahu, pengolah teri kering dan pedagang teri kering, maka dapat dihitung nilai tambahnya dari nelayan hingga ikan teri kering diterima oleh konsumen. 
Tabel 6. Nilai Tambah Perikanan Teri

\begin{tabular}{|c|c|c|c|c|c|}
\hline Pelaku & $\begin{array}{c}\text { Harga Jual } \\
\text { (Rp/Kg } \\
\text { Kering) }\end{array}$ & $\begin{array}{l}\text { Biaya } \\
\text { Produksi } \\
\text { (Rp/Kg } \\
\text { Kering) }\end{array}$ & $\begin{array}{c}\text { Biaya } \\
\text { Penjualan } \\
\text { (Rp/Kg } \\
\text { Kering) }\end{array}$ & $\begin{array}{c}\text { Marjin } \\
\text { Keuntungan } \\
\text { (Rp/Kg } \\
\text { Kering) }\end{array}$ & $\begin{array}{c}\% \\
\text { Kontribusi } \\
\text { Nilai } \\
\text { Tambah }\end{array}$ \\
\hline $\begin{array}{l}\text { Nelayan Bagan } \\
\text { Perahu }\end{array}$ & $\begin{array}{r}\text { Rp. } 6.487 \\
\text { (basah) x } 5= \\
\text { Rp. } 32.436\end{array}$ & $\begin{array}{r}\text { Rp. } 5.538 \text { X } \\
5=\text { Rp. } \\
27.692\end{array}$ & $\begin{array}{l}\text { Rp. } 151 \times 5 \\
\quad=\text { Rp. } 753\end{array}$ & $\begin{array}{l}\text { Rp. } 798 \times 5 \\
=\text { Rp. } 3.991\end{array}$ & $63 \%$ \\
\hline $\begin{array}{l}\text { Pengolah Ikan } \\
\text { Teri Kering }\end{array}$ & Rp. 36.000 & Rp. 33.491 & Rp. 1.069 & Rp. 1.440 & $23 \%$ \\
\hline $\begin{array}{l}\text { Pedagang Ikan } \\
\text { Teri Kering }\end{array}$ & Rp. 40.000 & Rp. 36.000 & Rp. 3.106 & Rp. 894 & $14 \%$ \\
\hline \multicolumn{4}{|r|}{ Nilai Tambah } & Rp. 6.325 & $100 \%$ \\
\hline
\end{tabular}

Keterangan: $1 \mathrm{Kg}$ teri kering memerlukan $5 \mathrm{Kg}$ teri segar (basah)

Hasil analisis nilai tambah menunjukkan bahwa kontributor terbesar nilai tambah adalah nelayan bagan perahu, yang mengeksploitasi sumberdaya perairan. Selanjutnya, diikuti oleh pengolah ikan yang melakukan transformasi produk, dari ikan segar menjadi ikan kering. Sedangkan pedagang ikan teri kering memberikan nilai tambah terkait dengan distribusi, yaitu dari produsen dibawa ke konsumen. Apabila nilai tambahnya ingin dinaikkan, maka proses value chain perlu diperbanyak, yaitu melalui diversifikasi produk bernilai tambah tinggi, misal dengan pendirian pabrik ikan teri kaleng untuk keperluan ekspor dan perdagangan nasional. Terkait dengan nilai marekting efficiency index $(\mathrm{ME}=3)$ yang nilainya lebih dari 1, maka mengindikasikan bahwa saluran distribusi perikanan teri Kabupaten Konawe Utara yang berlaku sekarang bersifat efisien.

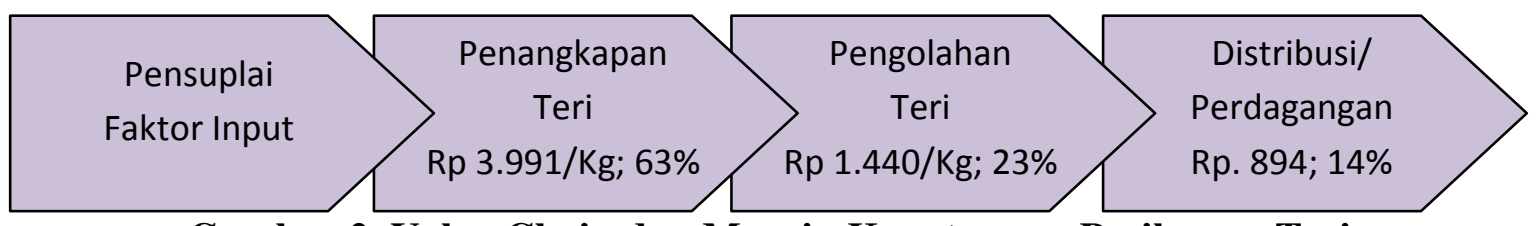

Gambar 2. Value Chain dan Margin Keuntungan Perikanan Teri

Tabel 7. Kontribusi Peran Pelaku Usaha Perikanan Teri

\begin{tabular}{|c|c|}
\hline Pelaku & Proses \\
\hline Pensuplai Faktor Input & $\begin{array}{l}\text { - Membeli atau memproduksi faktor input yang diperlukan } \\
\text { oleh nelayan bagan apung, diantaranya bambu, kayu, } \\
\text { jaring, lampu, mesin, bahan bakar minyak, dan } \\
\text { perbekalan (diantaranya beras, gula, kopi, teh, minyak } \\
\text { goreng, gas LPG), dsb. } \\
\text { - Menjual faktor input yang diperlukan untuk operasi } \\
\text { penangkapan ikan teri kepada nelayan bagan perahu }\end{array}$ \\
\hline Nelayan Bagan Perahu & $\begin{array}{l}\text { - Merancang dan membangun alat tangkap bagan perahu } \\
\text { - Mengeksploitasi sumberdaya ikan teri di perairan } \\
\text { Kabupaten Konawe Utara } \\
\text { - Mendistribusikan hasil tangkapan ikan teri ke fishing } \\
\text { base untuk dijual ke pengolah ikan teri }\end{array}$ \\
\hline Pengolah Ikan Teri Kering & $\begin{array}{l}\text { - Membersihkan ikan teri hasil tangkapan nelayan dan } \\
\text { menjadikan ikan teri segar sebagai bahan baku ikan } \\
\text { pengolahan ikan teri kering untuk meningkatkan daya }\end{array}$ \\
\hline
\end{tabular}




\begin{tabular}{|c|l|}
\hline Pelaku & \multicolumn{1}{|c|}{ Proses } \\
\hline & $\begin{array}{l}\text { tahan waktu keawetan ikan teri untuk kepentingan } \\
\text { konsumsi masyarakat } \\
\text { Mengemas ikan teri kering dan menjualnya kepada } \\
\text { pedagang ikan teri kering }\end{array}$ \\
\hline Pedagang Ikan Teri Kering & $\bullet \begin{array}{l}\text { Membeli ikan teri kering dari para pengolah ikan. } \\
\text { Mengemas kembali ikan teri kering yang dibeli dari para } \\
\text { pengolah ikan teri, serta mendistribusikannya kepada } \\
\text { konsumen, baik masyarakat Kabupaten Konawe Utara, } \\
\text { Kabupaten Konawe, Kota Kendari, maupu kabupaten } \\
\text { lain di wilayah Provinsi Sulawesi Tenggara. }\end{array}$ \\
\hline
\end{tabular}

\section{Analisis Permasalahan dan Alternatif Solusi}

Untuk pengembangan perikanan teri di Kabupaten Konawe Utara, maka perlu diidentifikasi permasalahan dan pengembangan alternatif solusinya. Menurut Parke (2014), perbaikan kinerja value chain dapat dilakukan dengan beberapa cara, antara lain: (1) perbaikan rencana, legal, dan kerangka manajemen sumberdaya, (2) meningkatkan kuantitas, keteraturan dan keberlanjutan produksi, (3) memperbaiki kualitas dan keamanan produk, (4) mengurangi waktu yang diperlukan untuk mencapai pelanggan, (5) meminimalkan biaya transaksi, dan (6) memperbaiki kapasitas pelaku agar mampu beradaptasi dengan teknologi dan pengembangan pasar.

Tabel 8. Analisis Permasalahan dan Alternatif Solusi

\begin{tabular}{|c|c|}
\hline \multicolumn{2}{|r|}{ Tahapan Value Chain } \\
\hline \multicolumn{2}{|c|}{ Pelaku: Pensuplai Faktor Input } \\
\hline Permasalahan & - Harga faktor input tertentu masih relatif mahal \\
\hline Penyebab & $\begin{array}{l}\text { - Jumlah pensuplai di dekat lokasi fishing base masih terbatas dan } \\
\text { beberapa } \\
\text { - Biaya pengiriman yang tinggi dan ketergantungan terhadap pensuplai } \\
\text { faktor produksi tertentu dari Makassar dan Surabaya, seperti pengadaan } \\
\text { mesin. }\end{array}$ \\
\hline $\begin{array}{l}\text { Alternatif } \\
\text { Solusi }\end{array}$ & $\begin{array}{l}\text { - Perbaikan infrastruktur transportasi agar biaya logistik semakin efisien } \\
\text { - Pendirian koperasi perikanan yang dapat menyediakan faktor produksi } \\
\text { dengan biaya yang wajar. }\end{array}$ \\
\hline \multicolumn{2}{|c|}{ Pelaku: Nelayan Bagan Perahu } \\
\hline Permasalahan & $\begin{array}{l}\text { - Produksi per trip masih relatif tinggi (325-525 Kg/trip), namun } \\
\text { cenderung mengalami penurunan secara time series } \\
\text { - Harga jual ikan teri hasil tangkapan relatif rendah } \\
\text { - Inefisiensi proses bongkar hasil tangkapan } \\
\text { - Suplai BBM masih mengandalkan penjual BBM eceran dengan harga } \\
\text { relatif mahal }\end{array}$ \\
\hline Penyebab & $\begin{array}{l}\text { - Kemungkinan sumberdaya ikan teri di perairan Kabupaten Konawe } \\
\text { Utara sedang mengalami deplesi. } \\
\text { - Belum ada tempat pelelangan ikan (TPI) yang dapat mendorong } \\
\text { terbentuknya harga yang saling menguntungkan bagi nelayan, pedagang } \\
\text { ikan dan pengolah ikan. } \\
\text { - Belum terdapat fasilitas pelabuhan perikanan yang memadai }\end{array}$ \\
\hline
\end{tabular}




\begin{tabular}{|c|c|}
\hline \multicolumn{2}{|r|}{ Tahapan Value Chain } \\
\hline & $\begin{array}{l}\text { - Belum tersedia stasiun penyedia BBM (SPDN) bersubsidi untuk nelayan } \\
\text { dengan kapal < } 30 \mathrm{GT}\end{array}$ \\
\hline $\begin{array}{l}\text { Alternatif } \\
\text { Solusi }\end{array}$ & $\begin{array}{l}\text { - Perlu penelitian mengenai MSY (maximum sustainable yield) dan } \\
\text { kebijakan kuota penangkapan ikan teri agar kelestarian terjaga. } \\
\text { - Perlu pembangunan pelabuhan perikanan yang didukung fasilitas pokok } \\
\text { (termasuk dermaga dan jetty), fungsional (termasuk TPI dan SPDN) dan } \\
\text { penunjang yang memadai. }\end{array}$ \\
\hline \multicolumn{2}{|c|}{ Pelaku: Pengolah Ikan Teri Kering } \\
\hline Permasalahan & $\begin{array}{l}\text { - Lokasi pengolahan belum memenuhi memenuhi prinsip hygiene dan } \\
\text { sanitasi sehingga kualitas ikan teri kering belum optimal } \\
\text { - Pengemasan produk masih sederhana }\end{array}$ \\
\hline Penyebab & $\begin{array}{l}\text { - Pelaku usaha pengolahan ikan teri kering belum menguasai prinsip- } \\
\text { prinsip hygiene dan sanitasi } \\
\text { - Pengemasan yang menarik dan baik belum dianggap penting }\end{array}$ \\
\hline $\begin{array}{l}\text { Alternatif } \\
\text { Solusi }\end{array}$ & $\begin{array}{l}\text { - Perlu dilakukan pembinaan mutu dan standarisasi kualitas produk teri } \\
\text { kering. }\end{array}$ \\
\hline \multicolumn{2}{|c|}{ Pelaku: Pedagang Ikan Teri Kering } \\
\hline Permasalahan & $\begin{array}{l}\text { - Pengemasan produk masih sederhana } \\
\text { - Biaya transportasi dan distribusi masih relatif tinggi }\end{array}$ \\
\hline Penyebab & $\begin{array}{l}\text { - Pengemasan yang menarik dan baik belum dianggap penting } \\
\text { - Kondisi infrastruktur transportasi masih belum memadai }\end{array}$ \\
\hline $\begin{array}{l}\text { Alternatif } \\
\text { Solusi }\end{array}$ & $\begin{array}{l}\text { - Perlu dilakukan pembinaan mutu dan standarisasi kualitas produk teri } \\
\text { kering. } \\
\text { - Perlu pembangunan infrastruktur pendukung agar perekonomian } \\
\text { perikanan dapat berjalan dengan efektif dan efisien. }\end{array}$ \\
\hline
\end{tabular}

\section{Kesimpulan}

Berdasarkan hasil analisis dapat diambil kesimpulan bahwa masing-masing pelaku dalam value chain perikanan teri di Kabupaten Konawe Utara memberikan kontribusi dalam peningkatan nilai tambah. Marjin pemasaran dan marjin keuntungan yang terbesar dinikmati oleh nelayan bagan perahu, diikuti oleh pengolah ikan teri dan pedagang ikan teri. Total nilai tambah perikanan teri di Kabupaten Konawe Utara adalah sebesar Rp. 6.325/kg teri kering.

\section{Saran}

Sebaiknya perlu dilakukan pembinaan mutu terhadap pelaku usaha perikanan teri yang masih bersifat tradisional, agar produknya semakin sesuai dengan prinsip hygiene dan sanitasi. Selain itu, juga perlu diteliti level eksploitasi sumberdaya ikan teri yang lestari (maximum sustainable yield atau MSY) untuk menghindari resiko deplesi sumberdaya ikan teri yang menyebabkan penurunan produksi dan kelangkaan sumberdaya ikan teri di perairan Kabupaten Konawe Utara. Apabila hasil kajian selanjutnya menunjukkan bahwa eksploitasi sumberdaya ikan teri masih dapat ditingkatkan, maka dapat dirancang pengembangan industri teri olahan untuk meningkatkan nilai tambah dan pemasarannya tidak hanya di Provinsi Sulawesi Tenggara. 


\section{Ucapan Terima Kasih}

Terima kasih kepada Sdr. Muhammad Agung Dharmawan yang telah membantu dalam pengumpulan data dan informasi.

\section{Daftar Pustaka}

Achchuthan, S., and Kajananthan, R. 2012. A Study on Value Chain Analysis in Dairy Sector Kilinochchi District, Sri Lanka. Global Journal of Management and Business Research, 12(21): 1-14.

BPS Kabupaten Konawe Utara, 2015 ${ }^{1}$. Kabupaten Konawe Utara dalam Angka 2015. BPS Kabupaten Konawe Utara. pp. 385

BPS Kabupaten Konawe Utara. 2015². Produk Domestik Regional Bruto Kabupaten Konawe Utara Menurut Lapangan Usaha 2010-2014. BPS Kabupaten Konawe Utara. pp.85

BPS Kabupaten Konawe Utara. 2015³. Kecamatan Lasolo Dalam Angka 2015. BPS Kabupaten Konawe Utara. pp.123.

BPS Provinsi Sulawesi Tenggara. 2013. Sulawesi Tenggara Dalam Angka 2013. BPS Provinsi Sulawesi Tenggara. pp. 458.

Dzanja, J., Kapondamgaga, P. and Tchale, H. 2013. Value Chain Analysis of Beef in Central and Southern Malawi (Case Studies of Lilongwe and Chikhwawa Districts). 4(6): 92102.

Eurofish International Organisation, 2012. Overview of the world's anchovy sector and trade possibilities for Georgian anchovy products. Eurofish International Organisation. pp. 40.

Gudmundsson, E., Asche, F. and Nielsen, M. 2006. Revenue Distribution Through The Seafood Value Chain. FAO. pp. 42.

Jung, S.C. 2014. The Analysis of Strategic Management Samsung Electronics Company through the Generic Value Chain Model Company. International Journal of Software Engineering and Its Applications. 8(12): 133-142.

Kabu, E., and Tira, D.S. 2015. Value Chain Analysis Towards Sustainability: A Case Study of Fishery Business in Kota Kupang, Indonesia. International Journal of Economics and Financial Issues. 5(Special Issue): 150-156.

KKP. 2014. Statistik Perikanan Tangkap Di Laut Menurut Wilayah Pengelolaan Perikanan Negara Republik Indonesia (WPPNRI), 2005-2013. KKP. pp. 448

Mwirigi, F.M and Theuri, F.S.. 2012. The Challenge of Value Addition in The Seafood Value Chain Along The Kenyan North Coast. International Journal of Business and Public Management 2(2): 51-56. 
Odebiyi, O.C, George, F.O.A, Odulate, D.O., Agbonlahor, M.U. and Olaoye, O. 2013. ValueChain Analysis for Coastal Fisheries Development in Nigeria. Global Journal of Science Frontier Research Agriculture and Veterinary. 13(11): 6-15.

O'Neill, E.D. 2013. A Value Chain Analysis of the Tuna Industry in Ghana. Thesis. Universidade do Algarve. pp. 125.

Parke, A. 2014. Value Chain Approaches In Fisheries Planning. CRFM, Policy Brief No. 4, September 2014. Pp 1-8.

Phiri, L.Y., Dzanja, J., Kakota, T. And Hara, M. 2013. Value Chain Analysis of Lake Malawi Fish: A Case Study of Oreochromis spp (Chambo). International Journal of Business and Social Science. 4(2): 170-181. 